\section{DNA Fingerprints in Plants Using Simple-sequence Repeat and Minisatellite Probes}

\author{
Dror Sharon, Avital Adato, Samir Mhameed, and Uri Lavi ${ }^{1}$ \\ Department of Fruit Breeding and Genetics, Agricultural Research \\ Organization, P.O. Box 6, Bet-Dagan 50250, Israel
}

\author{
Jossi Hillel \\ Department of Genetics, The Faculty of Agriculture, The Hebrew University \\ of Jerusalem, P.O. Box 12, Rehovot 76100, Israel \\ Maria Gomolka, Conny Epplen, and Jorg Thomas Epplen \\ Molekulare Humangenetik, MA, Ruhr-Universität, Universitätsstrasse 150, \\ W-4630 Bochum, Germany
}

Additional index words. breeding, DNA markers, identification, polymorphism

\begin{abstract}
Plant genomes contain polymorphic repetitive sequences that can be used as DNA markers. Minisatellites (16 to 64 bp per repeat) and simple-sequence repeats ( 2 to 6 bp per repeat) are the most polymorphic markers found in plant and animal genomes. In this study, the hybridizations between genomic DNA and variable number of tandem repeat probes were examined in Arabidopsis thaliana L. (Heynn), onion (Allium cepa L.), tomato (Lycopersicon esculentum L.), wheat (Triticum aestivum L.), avocado (Persea americana Mill.), litchi (Chinensis Sonn.), mango (Mangifera indica L.), and Carica species. Some of the probes detected polymorphic sequences in all the species, but others were useful only for one or two species. None of the probes gave clear band patterns in either onion or wheat. The in-gel hybridization method was similar to Southern blot hybridization using the simple-sequence repeat probes.
\end{abstract}

Eukaryotic genomes contain repetitive sequences, some of which can serve as genetic markers. Most polymorphic repetitive sequences are minisatellites and simple-sequence repeats (also called microsatellites). The polymorphism of this repetitive DNA results from the variable number of tandem repeats (VNTR) of a core sequence (Nakamura et al., 1987). Minisatellite regions contain a core sequence from 16 to $64 \mathrm{bp}$ long and were the first used to detect multiple-band patterns that are highly polymorphic in humans and, thus, are used for DNA fingerprints (Jeffreys et al., 1985). These band patterns were generated by hybridization of probes to genomic DNA digested with a restriction enzyme (the restriction sites flank the repeat motif). The simple-sequence repeat regions consist of 2- to 6-bp sequences (Weising et al., 1991) and are a major source of genomic variation (Tautz et al., 1986).

Received for publication 1 Feb. 1994. Accepted for publication 24 Sept. 1994. The oligonucleotide probes are subject to patent application. Commercial inquiries should be directed to FRESENIUS AG, Oberursel, Germany. We thank A.J. Jeffreys for using probes 33.6 and 33.15, Hazera Co. for the tomato plants, Yossi Hirshberg for the Arabidopsis plants, and Haim Rabinovitch for the onion plants. Contribution no. 1285-E, 1994 series from the Agricultural Research Organization, The Volcani Center, Bet-Dagan, Israel. The cost of publishing this paper was defrayed in part by the payment of page charges. Under postal regulations, this paper therefore must be hereby marked advertisement solely to indicate this fact.

${ }^{1}$ To whom reprint requests should be addressed.
After digestion and electrophoresis, two techniques can be used to prepare the DNA for fingerprints: Southern blotting (gel is blotted onto a membrane that is then hybridized with the probe) or in-gel hybridization (gel is dried and hybridization with simple-sequence repeats takes place directly in the gel). Both techniques have been used to produce polymorphic DNA fingerprint patterns in many species, including humans (Ali et al., 1986; Jeffreys et al., 1985), various other animals (Epplen, 1988; Hillel et al., 1989, 1992), and plants (Beyermann et al., 1992; Dallas, 1988; Lavi et al., 1991; Nybom and Hall, 1991; Sharon et al., 1992; Tzuri et al., 1991; Vosman et al., 1992; Weising et al., 1991). The in-gel hybridization approach (Schaefer et al., 1988) for simple-sequence repeat DNA fingerprints is more efficient and faster than Southern blot hybridization by saving blotting and prehybridization procedures. In the human genome, many thousands of simple-sequence repeat loci have been detected and used for mapping (National Institute for Health-Center d'Etude du Polymorphisme Humain Collaborative Mapping Group, 1992; Weissenbach et al., 1992).

Despite many species examined for DNA fingerprints, to our knowledge no information is available for Arabidopsis, litchi, mango, onion, and wheat, and limited information is available concerning avocado (Lavi et al., 1991), Carica (Sharon et al., 1992), and tomato (Vosman et al., 1992).

Our study evaluated DNA fingerprints obtained by either simple-sequence repeat or minisatellite probes in Arabidopsis, onion, tomato, wheat, avocado, litchi, mango, and Carica. Using Southern blotting for simplesequence repeat fingerprints was compared with in-gel hybridization.

\section{Materials and Methods}

The following plant material was used in this study: Arabidopsis-'Columbia', 'Landsberg', and 'Niderzants'; avocado'Fuerte', 'Nabal', 'Reed', and 'Sharwill'; Carica species (Manshardt and Wenslaff, 1989)-C. quercifolia, C. papaya, C. pentagona, and $C$. pubescens; litchi-'Fay Zee Siu', and 'Vai Chee'; mango_-'Yasmin', ' $1 / 5$ ', and 'Palmer'; and tomato-'Hazera 1', 'Hazera 2', 'Hazera 3', 'Hazera 4', 'Hazera 5', and 'Hazera 6'.

DNA was isolated from leaves by modifying the cetyltrimethyl ammonium bromide (CTAB) method (Murray and Thompson, 1980). The extraction buffer contained $2 \%$ CTAB, 0.1 м Tris-HCl (pH 8), 0.02 м ethylenediamine tetraacetic acid (EDTA), 1.4 $\mathrm{M} \mathrm{NaCl}$, and 1\% 2-mercaptoethanol. Chloroform extraction was performed three times. Two volumes of precipitation buffer were added to the final aqueous phase. The precipitation buffer contained $1 \%$ CTAB, $0.05 \mathrm{M}$ Tris- $\mathrm{HCl}(\mathrm{pH} \mathrm{8)}, 0.01$ м EDTA, and $1 \% 2$ mercaptoethanol. Nucleic acids were dissolved in $1 \mathrm{M} \mathrm{CsCl}$, precipitated with ethanol, and redissolved in $10 \mathrm{~mm}$ Tris- $\mathrm{HCl}(\mathrm{pH} 8)$ and 1 mM EDTA.

Ten-microgram DNA samples were digested with one of the following restriction enzymes: Dra I, EcoR I, or Hinf I (New England Biolabs, Beverly, Mass.) according to the supplier's recommendations. Samples were loaded onto 30- or 20-cm-long (in-gel hybridization or Southern blot hybridization, respectively), $0.8 \%$ agarose gels in $0.045 \mathrm{M}$ Trisborate and $0.001 \mathrm{MEDTA}$ (pH 8) (TBE buffer) and electrophoresed at $1.5 \mathrm{~V} \cdot \mathrm{cm}^{-1}$.

Gels for in-gel hybridization were dried on a vacuum gel dryer, denatured in $0.5 \mathrm{M} \mathrm{NaOH}$ and $0.15 \mathrm{M} \mathrm{NaCl}$ for $30 \mathrm{~min}$, neutralized in 0.5 $\mathrm{M}$ Tris- $\mathrm{HCl}(\mathrm{pH} 8)$ and $0.15 \mathrm{M} \mathrm{NaCl}$ for $30 \mathrm{~min}$, and equilibrated in $6 \times$ SSC $(20 \times$ SSC : $3 \mathrm{~m}$ $\mathrm{NaCl}, 0.3 \mathrm{M}$ sodium citrate) before hybridization. Oligonucleotides were 5-prime end-labeled by a T4-polynucleotide kinase reaction (Fritsch et al., 1989) using $\gamma^{32}$ P-labeled dATP (Amersham International, Amersham, U.K.) Labeled probes were purified through a DE52 column (Whatman, Maidstone, England) according to Schaefer et al. (1988).

Hybridization of dried gels with seven simple-sequence repeat probes was performed for 1 to $2 \mathrm{~h}$ in hybridization buffer [ $5 \times \mathrm{SSPE}$ $\left(20 \times \mathrm{SSPE}=3 \mathrm{M} \mathrm{NaCl}, 0.2 \mathrm{M} \mathrm{NaH}_{2} \mathrm{PO}_{4} \cdot \mathrm{H}_{2} \mathrm{O}\right.$, $0.02 \mathrm{M} \mathrm{Na}_{2}$ EDTA $\left.\cdot \mathrm{H}_{2} \mathrm{O}\right), 5 \times$ Denhart's solution $(100 \times$ Denhardt's $=2 \%$ polyvinyl-pyrroldone $40,2 \%$ bovine serum albumin, and $2 \%$ ficoll 400), $0.1 \%$ SDS, $10 \mathrm{mg}$ sonicated, denatured E. coli $\mathrm{DNA} / \mathrm{ml}$ at the respective hybridization temperature $\left({ }^{\circ} \mathrm{C}\right):(\mathrm{GATA})_{4}$ and $(\mathrm{AAC})_{5}=$ $35 ;(\mathrm{GGAT})_{4},(\mathrm{CA})_{8},(\mathrm{GAA})_{6}$, and $(\mathrm{GACA})_{4}=$ 43; and $(\mathrm{GTG})_{5}=45$. After hybridization, gels were washed in $6 \times \mathrm{SSC}$ for $20 \mathrm{~min}$ at room 
temperature, followed by a wash at the hybridization temperature for 1 to $2 \mathrm{~min}$, followed by another 20-min wash in $6 \times \mathrm{SSC}$ at room temperature.

Gels for Southern blot hybridization were blotted onto Hybond-N+ membranes according to the supplier's recommendations. Membrane-bound DNA was hybridized to minisatellite probes 33.6 and 33.15 (Jeffreys et al., 1985), which were labeled with ${ }^{32} \mathrm{P}-\mathrm{dCTP}$ by random priming (Feinberg and Vogelstein, 1983), or to simple-sequence repeat probes $\left[(\mathrm{GGAT})_{4},(\mathrm{GACA})_{4}\right.$, and $\left.(\mathrm{GATA})_{4}\right]$. Prehybridization, hybridization, and washes were performed according to Hillel et al. (1989).

The efficiency of each probe was tested by two criteria: 1) the level of polymorphism based on the number of bands specific to the tested genetic groups and 2) the quality of DNA fingerprint patterns, based on the ratio between the specific signals and the background.

\section{Results and Discussion}

Figure 1 presents the DNA fingerprints of Arabidopsis, avocado, and litchi using Southern blot hybridization with probe 33.6 and ingel hybridization with simple-sequence repeat probes. The two minisatellite probes (33.6 and 33.15) hybridized to Arabidopsis genome, but only 33.6 detected high-quality patterns of polymorphic bands. The informative bands from probe 33.6 ranged from 3 to $22 \mathrm{~kb}$ (Fig. 1A). The simple-sequence repeat probe (GAA) detected informative patterns between 2 to 3.5 $\mathrm{kb}$ and a few bands between 10 to $22 \mathrm{~kb}$ in length (Fig. 1A). Each of the probes detected relatively few bands, but the polymorphic patterns allow identification of each cultivar. The other simple-sequence repeat probes $\left[(\mathrm{GGAT})_{4},(\mathrm{AAC})_{5},(\mathrm{GTG})_{5},(\mathrm{GATA})_{4}\right.$, and $(\mathrm{CA})_{8}$ ] did not provide informative patterns (Table 1). The fact that probes 33.6 and (GAA) detected polymorphic DNA fingerprint patterns indicates that the small genome of Arabidopsis does contain polymorphic repeated sequences. However, it is noteworthy that most of the simple-sequence repeat probes did not hybridize at all to the Arabidopsis genome. The recommended enzyme for Arabidopsis is Hind III, and the probes are 33.6 and (GAA) 6 .

The avocado genome contains most of the simple-sequence repeat sequences that we used. Probe (GATA) $)_{4}$ detected highly polymorphic patterns (Fig. 1B), but (GTG) $)_{5}$ and (GACA) $)_{4}$ (Table 1) detected medium-quality polymorphic patterns. Probes $(\mathrm{GGAT})_{4},(\mathrm{AAC})_{5},(\mathrm{CA})_{8}$, and (GAA) ${ }_{6}$ provided poor and nonresolvable patterns (Table 1). Regarding the minisatellite probes, 33.6 was useful for avocado fingerprinting, and probe 33.15 generated fingerprints of low quality and low levels of polymorphism. Previously, avocado DNA fingerprints were obtained by minisatellite probes using Southern blot hybridizations (Lavi et al., 1991). In this study, avocado DNA fingerprints were obtained with additional simplesequence repeats by in-gel hybridization as well. The best DNA fingerprints for avocado were obtained using probe (GATA) $)_{4}$, hybridized to genomic DNA digested with Hinf I.

In litchi, the simple-sequence repeats $(\text { GGAT })_{4}$ and (GATA) ${ }_{4}$ (Fig. 1C) and the minisatellite probes (33.15 and 33.6) detected medium levels of polymorphism and bands of reasonable quality (Table 1 ). The patterns obtained using probes $(\mathrm{AAC})_{5}$ and $(\mathrm{GTG})_{5}$ were less resolvable (Table 1$)$. The best probes for litchi DNA fingerprinting were (GGAT) and (GATA) $)_{4}$ and the minisatellites 33.15 and 33.6. The genomic DNA was digested with either Hinf I or Dra I.

Figure 2 presents the DNA fingerprints of

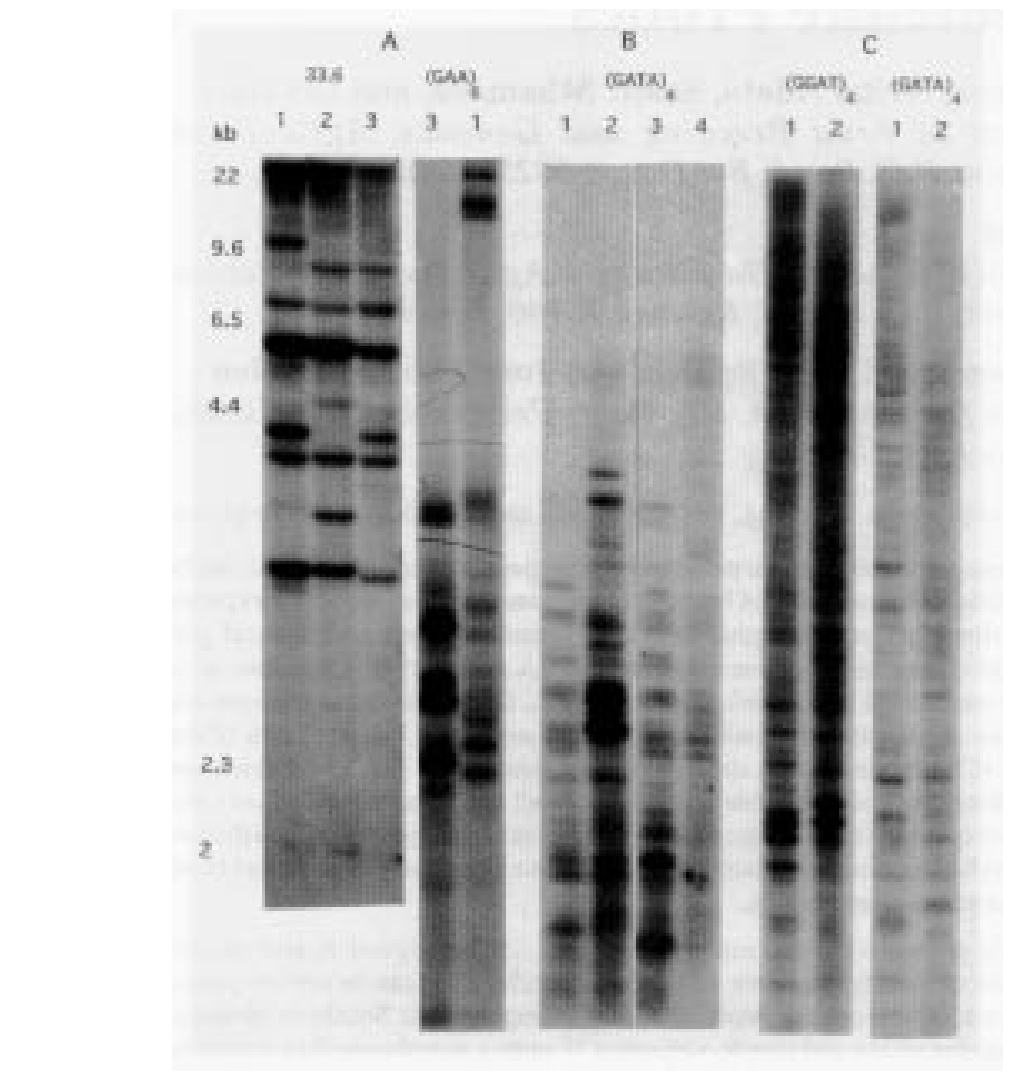

Fig. 1. DNA fingerprints of (A) Arabiodopsis, (B) avocado, and (C) litchi using Southern blot hybridization with probe 33.6 and in-gel hybridization with simple-sequence repeat probes. Lanes: (A) (enzyme-Hind III) 1) 'Niderzants', 2) 'Landsberg', and 3) 'Columbia'; (B) (enzyme-Hinf I) 1) 'Nabal', 2) 'Reed', 3) 'Sharwill', and 4) 'Fuerte'; (C) (enzyme-Hind III) 1) 'Fay Zee Siu' and 2) 'Vai Chee'. Size markers are given in kilobases.

Table 1. Oligonucleotide fingerprinting in eight plant species.

\begin{tabular}{|c|c|c|c|c|c|c|c|c|c|}
\hline Variable & $\begin{array}{l}\text { Simple- } \\
\text { sequence } \\
\text { repeats }^{\mathrm{z}}\end{array}$ & Arabidopsis & Avocado & Carica & Litchi & Mango & Onion & Tomato & Wheat \\
\hline \multicolumn{10}{|l|}{ Probe } \\
\hline \multirow[t]{2}{*}{$(\mathrm{GGAT})_{4}$} & $\mathrm{P}$ & - & ++ & +++ & ++ & ++ & - & +++ & + \\
\hline & Q & - & + & ++ & ++ & ++ & + & +++ & + \\
\hline \multirow[t]{2}{*}{$(\mathrm{AAC})_{5}$} & $\mathrm{P}$ & - & + & - & + & + & + & ++ & + \\
\hline & Q & - & + & - & + & ++ & + & +++ & + \\
\hline \multirow[t]{2}{*}{$(\mathrm{GTG})_{5}$} & $\mathrm{P}$ & - & ++ & + & ++ & + & + & ++ & - \\
\hline & Q & - & ++ & ++ & + & ++ & + & ++ & - \\
\hline \multirow[t]{2}{*}{$(\mathrm{CA})_{8}$} & $\mathrm{P}$ & + & ++ & + & - & - & - & ++ & - \\
\hline & Q & + & + & + & - & - & + & + & - \\
\hline \multirow[t]{2}{*}{$(\text { GATA })_{4}$} & $\mathrm{P}$ & - & +++ & + & ++ & + & - & +++ & - \\
\hline & Q & - & ++ & ++ & ++ & + & - & +++ & - \\
\hline \multirow[t]{2}{*}{$(\mathrm{GAA})_{6}$} & $\mathrm{P}$ & ++ & - & + & - & - & - & ++ & + \\
\hline & Q & +++ & - & + & - & - & + & ++ & + \\
\hline \multirow[t]{2}{*}{$(\mathrm{GACA})_{4}$} & $\mathrm{P}$ & - & ++ & +++ & - & ++ & - & ++ & - \\
\hline & Q & - & ++ & ++ & - & ++ & - & ++ & - \\
\hline \multicolumn{10}{|c|}{ Minisatellites } \\
\hline \multirow[t]{2}{*}{33.6} & $\mathrm{P}$ & ++ & ++ & + & ++ & +++ & + & ++ & - \\
\hline & Q & +++ & ++ & +++ & ++ & ++ & + & ++ & - \\
\hline \multirow[t]{2}{*}{33.15} & $\mathrm{P}$ & + & - & ++ & ++ & - & + & ++ & - \\
\hline & Q & ++ & + & +++ & ++ & - & + & ++ & - \\
\hline
\end{tabular}

${ }^{\mathrm{z}} \mathrm{P}=$ polymorphism information based on band sharing (BS) level: - , monomorphic $(\mathrm{BS}=100 \%) ;, \mathrm{BS}$ between $85 \%$ and $99 \% ;++$, BS between $60 \%$ and $84 \% ;+++$, BS between $40 \%$ and $59 \%$. Q $=$ quality assessed on the ratio of signal to background. Quality ranging from low (-) to high (+++). 
Carica species and mango cultivars using Southern blot hybridization. In several Carica species and especially in Carica papaya, DNA fingerprints were obtained with probes $(\text { GGAT })_{4}$ and (GACA $)_{4}$ using restriction enzyme Dra I (Fig. 2A, Table 1). Both probes gave a medium number of highly polymorphic bands. Probe $(\mathrm{AAC})_{5}$ did not hybridize to the Carica genome, and probes $(\mathrm{GTG})_{5},(\mathrm{CA})_{8}$, $(\text { GATA })_{4}$, and (GAA) 6 provided noninformative DNA fingerprint patterns (Table 1). The two minisatellite probes tested (33.6 and 33.15) were useful for $C$. papaya DNA fingerprinting. In a previous study, DNA fingerprints of $C$. papaya and other Carica species were obtained with minisatellites and simplesequence repeat probes $(\mathrm{CA})_{12}$ and $(\mathrm{GTG})_{5}$ (Sharon et al., 1992). The polymorphism and band quality detected by these probes were low, and thus, in our study, additional simplesequence repeat probes were used. As a result, the two probes $(\mathrm{GGAT})_{4}$ and $(\mathrm{GACA})_{4}$ were useful.

The simple-sequence repeat probes $(\text { GACA })_{4}$ (Fig. 2B) and (GGAT) $)_{4}$ detected a medium level of polymorphism in mango, with band sizes ranging from 2 to $22 \mathrm{~kb}$ (Table 1). The simple-sequence repeats (AAC) $)_{5}$, $(\mathrm{GTG})_{5}$, and (GATA $)_{4}$ detected low levels of polymorphism, but probes $(\mathrm{CA})_{8}$ and (GAA) 6 did not hybridize with the mango genome. The minisatellite probe 33.6 detected highly polymorphic bands of medium quality (Fig. 2B), and probe 33.15 detected only one monomorphic band. The most informative probe for mango fingerprinting was minisatellite 33.6 following digestion with $E c o R$ I; the simplesequence repeat probes (GGAT) $)_{4}$ and (GACA) ${ }_{4}$ were less informative.

All VNTR probes used in this study were hybridized to the tomato genome. Tomato cultivars were digested with Dra I or HinfI and hybridized to simple-sequence repeat probes by in-gel hybridization or by Southern blotting. The minisatellite probes were hybridized after Southern blotting. The minisatellite probes 33.6 (Fig. 3A) and 33.15 detected DNA bands characterized by a medium level of polymorphism and medium quality. The simplesequence repeat probes (GATA) ${ }_{4}$ (Fig. 3B) and (GGAT) $)_{4}$ (Fig. 3C) detected high-quality and highly polymorphic DNA fingerprint patterns, with bands ranging from 1.5 to $22 \mathrm{~kb}$ in length. Some of the bands detected by both probes and with the same molecular weight showed the same type of variation. This finding suggests that these fragments have $(\text { GGAT })_{n}$ and (GATA) $)_{n}$ sequences.

Two cultivars were used to compare the Southern blot and in-gel hybridization methods (Fig. 3B). There was no significant difference between the quality of the DNA fingerprint patterns between the two methods. Probes $(\text { AAC })_{5}$ (Fig. 3C) and (GAA) 6 (Table 1) detected medium-quality and medium polymorphic patterns, with bands ranging from 1.5 to $22 \mathrm{~kb}$ in length. Probe $(\mathrm{GTG})_{5}$ detected highquality patterns of a medium level of polymorphism ranging from 2.5 to $22 \mathrm{~kb}$ (Fig. 3C). Probe $(\mathrm{CA})_{8}$ detected medium level of polymorphism but with rather low quality (Table
1). An average total of 155 bands per individual were detected in tomato by the nine VNTR probes, of which an average of 93 were polymorphic. Based on these results, the rec- ommendation for tomato fingerprinting is the combination of the restriction enzyme Dra I and the probes (GGAT) $)_{4}$ or (GATA) $)_{4}$. Vosman et al. (1992) suggested that (GATA) $)_{4}$ is the

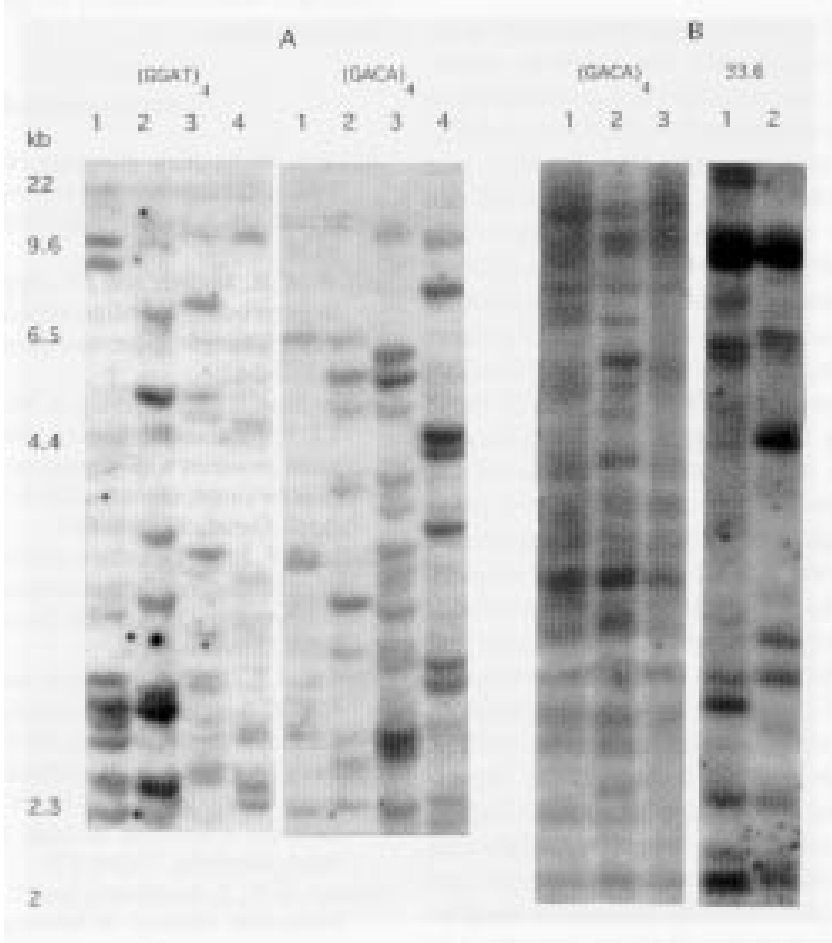

Fig. 2. Simple-sequence repeat and minisatellite DNA fingerprints of (A) Carica species and (B) mango as produced by Southern blot hybridization. Lanes: (A) (enzyme-DraI) 1) C. quercifolia, 2) C. papaya, 3) C. pubescens, and 4) C. pentagona; (B) (enzyme-EcoR I) 1) '1/5', 2) 'Yasmin', and 3) 'Palmer'. Size markers are given in kilobases.

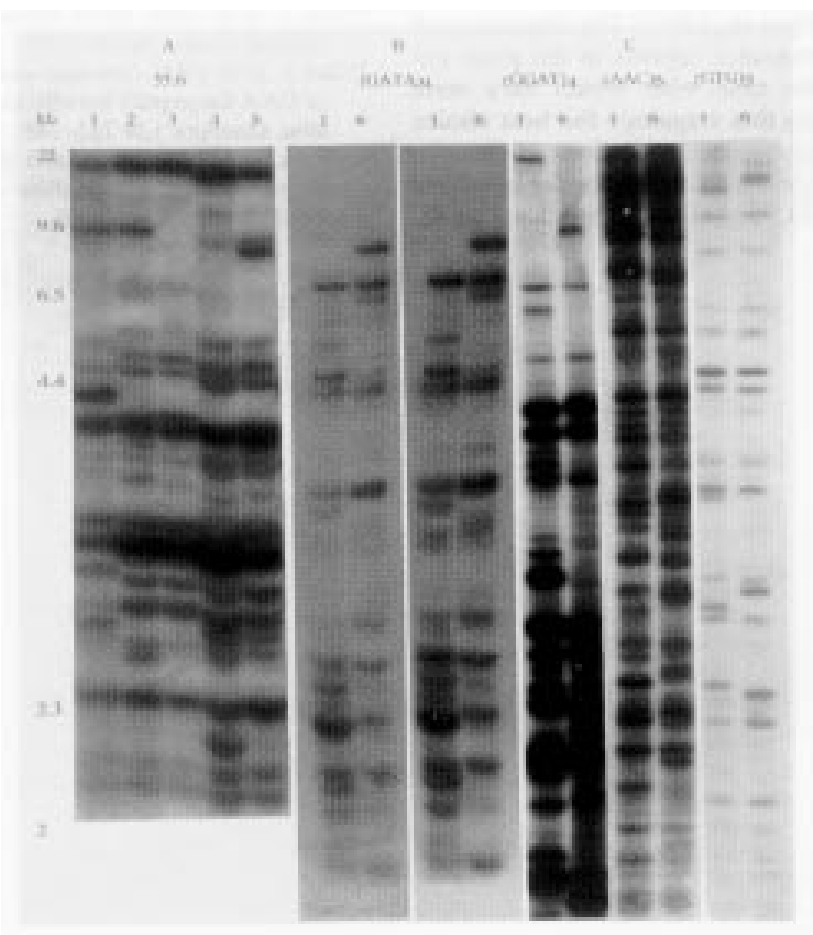

Fig. 3. Tomato DNA fingerprints: (A) minisatellite probes (by Southern blot hybridization), (B) simplesequence repeat probes - a comparison between (left) Southern blot hybridization and (right) in-gel hybridization, and (C) simple-sequence repeat probes (by in-gel hybridization). Lanes: 1) 'Hazera' 1; 2) 'Hazera' 2; 3) 'Hazera' 3; 4) 'Hazera' 4; 5) 'Hazera' 5; and 6) 'Hazera' 6. DNA was digested with Dra I. Size markers are given in kilobases. 
best probe to produce DNA fingerprints in tomato by Southern blot hybridization. Our study suggests that (GATA) ${ }_{4}$ and (GGAT) can be applied using in-gel hybridization as well.

None of the probes used in our study gave satisfactory fingerprints for onion or wheat. For both species, some probes generated low levels of polymorphism [33.15, 33.6, (AAC) $)_{5}$, and $(\mathrm{GTG})_{5}$ in onion; $(\mathrm{GGAT})_{4},(\mathrm{AAC})_{5}$, and $(\mathrm{GAA})_{6}$ in wheat]. The other probes did not hybridize to either the onion or the wheat genomes (Table 1). The hybridization of some simple-sequence repeat probes resulted in smears, indicating many repetitive loci in these genomes. Therefore, searching for microsatellite (Akkaya et al., 1992) markers in these species using these sequences would be reasonable. We assume that the cause of the smear patterns in wheat resulted from its polyploidy and high content of repetitive sequences. We are not aware of DNA studies of onion.

In our study, we used Southern blot hybridization (for tomato, Carica, and mango) and in-gel hybridization (for tomato, Arabidopsis, avocado, and litchi) for minisatellite hybridization and simple-sequence repeat probes. Both methods produced clear DNA fingerprint patterns. When applying the simplesequence repeat probes, we recommend using in-gel hybridization, which is a simple and quick procedure. Among the seven simplesequence repeat probes that we examined in this study, (GATA) $)_{4}$ and $(\text { GGAT })_{4}$ are the most common and useful in plants. In previous studies, mainly $(\mathrm{GATA})_{4}$ and $(\mathrm{CAC})_{5}$ were useful for identification (Beyermann et al., 1992; Weising et al., 1991). The abundance of the simple-sequence repeats in the plant genome and the ease with which they were applied makes this sequence the best choice for DNA fingerprints. In previous studies, the minisatellite probe 33.6 gave better results in plants than 33.15 (Dallas, 1988; Lavi et al.,
1991); our data confirm this finding. Probe 33.15 was useful only for fingerprinting Carica species. The DNA fingerprints described in our study can be used for identification of cultivars and estimation of genetic distances between them.

\section{Literature Cited}

Akkaya, M.S., A.A. Bhagwat, and P.B. Cregan. 1992. Length polymorphisms of simple sequence repeat DNA in soybean. Genetics 132:11311139.

Ali, S., C.R. Muller, and J.T. Epplen. 1986. DNA fingerprinting by oligonucleotide probes specific for simple sequence repeats. Human Genet. 4:239-243.

Beyermann, B., P. Nurnberg, A. Weike, M. Meixner, J.T.Epplen, and T. Borner. 1992. Fingerprinting plant genomes with oligonucleotide probes specific for simple repetitive DNA sequences. Theor. Appl. Genet. 83:691-694.

Dallas, J.F. 1988. Detection of DNA "fingerprints" of cultivated rice by hybridization with a human minisatellite DNA probe. Proc. Natl. Acad. Sci. USA 85:6831-6835.

Epplen, J.T. 1988. On simple sequence repeated GAT/CA sequences in animal genomes: A critical reappraisal. J. Hered. 79:409-417.

Feinberg, A.P. and B. Vogelstein. 1983. A technique for radiolabelling DNA restriction endonuclease fragments to high specific activity. Anal. Biochem. 132:6-13.

Fritsch, E.P., J. Sambrook, and T. Maniatis. 1989. Molecular cloning: A laboratory manual. 2nd ed. Cold Spring Harbor Univ. Press, Cold Spring Harbor, N.Y.

Hillel, J., E.A. Dunnington, and P.B. Siegel. 1992. DNA markers in poultry breeding and genetic analysis. Poultry Sci. Rev. 4:169-186.

Hillel, J., et al. 1989. DNA fingerprints of poultry. Animal Genet. 30:145-155.

Hillel, J., et al. 1990. Genomic selection application of DNA fingerprint for efficient gene introgression. Genetics 124:783-789.

Jeffreys, A.J., V. Wilson, and S.L. Thein. 1985. Hypervariable 'minisatellite' regions in human DNA. Nature 314:67-73.
Lavi, U., J. Hillel, A. Vainstein, E. Lahav, and D. Sharon. 1991. Application of DNA fingerprints for identification and analysis of avocado. J. Amer. Soc. Hort. Sci. 116:1078-1081.

Manshardt, R.M. and T.F. Wenslaff. 1989. Interspecific hybridization of papaya with other Carica species. J. Amer. Soc. Hort. Sci. 114:689-694.

Murray, M.G. and W.F. Thompson. 1980. Rapid isolation of high molecular weight plant DNA. Nucleic Acids Res. 8:4321-4325.

Nakamura, Y., et al. 1987. Variable number of tandem repeat (VNTR) markers for human gene mapping. Science 235:1616-1622.

National Institute for Health-Center d'Etude du Polymorphisme Humain Collaborative Mapping Group. 1992. A comprehensive genetic linkage map of the human genome. Science 258:67-86.

Nybom, H. and H.K. Hall. 1991. Minisatellite DNA 'fingerprints' can distinguish Rubus cultivars and estimate their degree of relatedness. Euphytica 53:107-114.

Schaefer, R., H. Zischler, U. Birsner, A. Becker, and J.T. Epplen. 1988. Optimized oligonucleotide probes for DNA fingerprinting. Electrophoresis 9:369-374.

Sharon, D., J. Hillel, A. Vainstein, and U. Lavi. 1992. Application of DNA fingerprints for identification and genetic analysis of Carica papaya and other Carica species. Euphytica 62:119126.

Tautz, D., M. Trick, and G.A. Gavora. 1986. Cryptic simplicity in DNA is a major source of genetic variation. Nature 322:652-656.

Tzuri, G., J. Hillel, U. Lavi, A. Haberfeld, and A. Vainstein. 1991. DNA fingerprint analysis of ornamented plants. Plant Sci. 76:91-97.

Vosman, B., P. Arens, W. Rus-Kortekaas, and J.M. Smulders. 1992. Identification of highly polymorphic DNA regions in tomato. Theor. Appl. Genet. 85:239-244.

Weising, K., J. Ramser, D. Kaemmer, G. Kahl, and J.T. Epplen. 1991. Oligonucleotide fingerprinting in plants and fungi, p. 312-329. In: T. Burke, G. Dolf, A.J. Jeffreys, and R. Wolff (eds.). DNA fingerprinting approaches and application. Birkhauser Verlag, Basel/Switzerland.

Weissenbach, J., et al. 1992. A second-generation linkage map of the human genome. Nature 359:794-801. 